\title{
The accuracy of endoscopic ultrasonography with fine-needle aspiration, integrated positron emission tomography with computed tomography, and computed tomography in restaging patients with esophageal cancer after neoadjuvant chemoradiotherapy
}

Robert James Cerfolio, MD, FACS, FCCP, ${ }^{\mathrm{a}, \mathrm{b}}$ Ayesha S. Bryant, MSPH, ${ }^{\mathrm{c}}$ Buddhiwardhan Ohja, MD, MPH, ${ }^{\mathrm{d}}$ Alfred A. Bartolucci, PhD, and Mohamad A. Eloubeidi, MD, MHS, FACP ${ }^{f}$

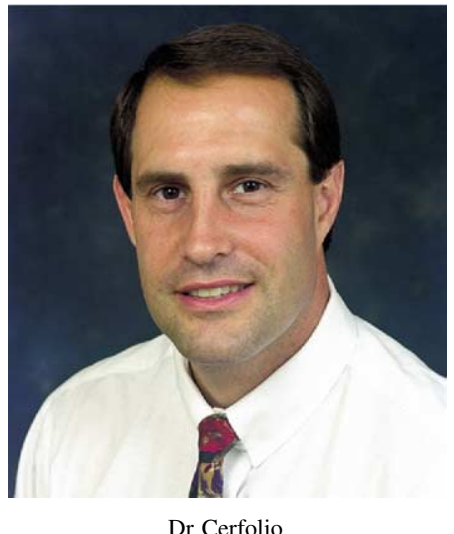

From the Section of Thoracic Surgery, ${ }^{a}$ the Division of Nuclear Radiology, ${ }^{\mathrm{d}}$ and the Department of Medicine, Division of Gastroenterology and Hepatology, ${ }^{\mathrm{f}}$ University of Alabama at Birmingham, Birmingham, Ala; the Division of Cardio-Thoracic Surgery, Department of Surgery, ${ }^{b}$ the Birmingham Veterans Administration Hospital, Birmingham, Ala; and the Departments of Epidemiology ${ }^{\mathrm{c}}$ and Biostatistics, ${ }^{\mathrm{e}}$ University of Alabama at Birmingham School of Public Health, Birmingham, Ala.

Read at the Thirtieth Annual Meeting of The Western Thoracic Surgical Association, Maui, Hawaii, June 23-26, 2004.

Received for publication June 26, 2004; revisions received Nov 8, 2004; accepted for publication Dec 22, 2004.

Address for reprints: Robert J. Cerfolio, MD, Division of Cardiothoracic Surgery, University of Alabama at Birmingham, 1900 University Blvd, THT 712, Birmingham, AL 35294 (E-mail: robert.cerfolio@ ccc.uab.edu)

J Thorac Cardiovasc Surg 2005;129:1232-41 $0022-5223 / \$ 30.00$

Copyright (C) 2005 by The American Association for Thoracic Surgery

doi:10.1016/j.jtcvs.2004.12.042
Background: Patients with esophageal cancer who receive neoadjuvant chemoradiotherapy are restaged with computed tomography (CT), endoscopic ultrasound with fine needle aspiration (EUS-FNA), and integrated positron emission computed tomography (FDG-PET/CT), and the results affect treatment.

Methods: This is a prospective trial on a consecutive series of patients who had initial chest, abdomen, and pelvis CT scan; EUS-FNA; and fluoro-2-deoxy-Dglucose (FDG)-integrated PET/CT; neoadjuvant chemoradiotherapy; repeat staging tests; pathologic staging; and, if appropriate, resection with lymphadenectomy. The primary objective was to assess the accuracy of these 3 tests in restaging patients after neoadjuvant therapy.

Results: There were 48 patients (41 men), and 41 underwent Ivor Lewis esophagogastrectomy with lymphadenectomy. The accuracy of each test for distinguishing pathologic T4 from T1 to T3 disease is $76 \%, 80 \%$, and $80 \%$ for CT scan, EUS-FNA and FDG-PET/CT, respectively. The accuracy for nodal disease was $78 \%, 78 \%$, and 93\% for CT scan, EUS-FNA and FDG-PET/CT, respectively $(P=.04)$. FDG$\mathrm{PET} / \mathrm{CT}$ correctly identified M1b disease in 4 patients, falsely suggested it in 4 patients, and missed it in 2 patients, whereas for CT, it was 3, 3, and 3 patients. Fifteen $(31 \%)$ patients were complete responders, and FDG-PET/CT accurately predicted complete response in $89 \%$ compared with $67 \%$ for EUS-FNA $(P=.045)$ and $71 \%$ for $\mathrm{CT}(P=.05)$.

Conclusions: FDG-PET/CT is more accurate than EUS-FNA and CT scan for predicting nodal status and complete responders after neoadjuvant therapy in patients with esophageal cancer. FDG-PET/CT and CT alone provide targets for biopsy, but results are often falsely positive.

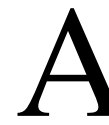
pproximately 14,000 persons are given diagnoses of esophageal cancer each year in the United States, and 13,000 will eventually die of it. ${ }^{1}$ The 5-year survival is stage dependent, ${ }^{2}$ and when surgical intervention alone is performed, it ranges from $15 \%$ to $24 \%{ }^{3}$ Because of the poor results of resection alone, most physicians in North America favor the use of neoadjuvant cisplatin-based chemoradiotherapy. This bias is true despite the fact that there are few prospective randomized data to support its routine use. ${ }^{4-9}$ Because surgical resection is often reserved for only those who respond to their preoperative treatment or for those in whom disease does not progress, surgeons are often asked to reassess patients for resection after neoadjuvant therapy. The most commonly used staging modalities are computed tomography (CT) 
A

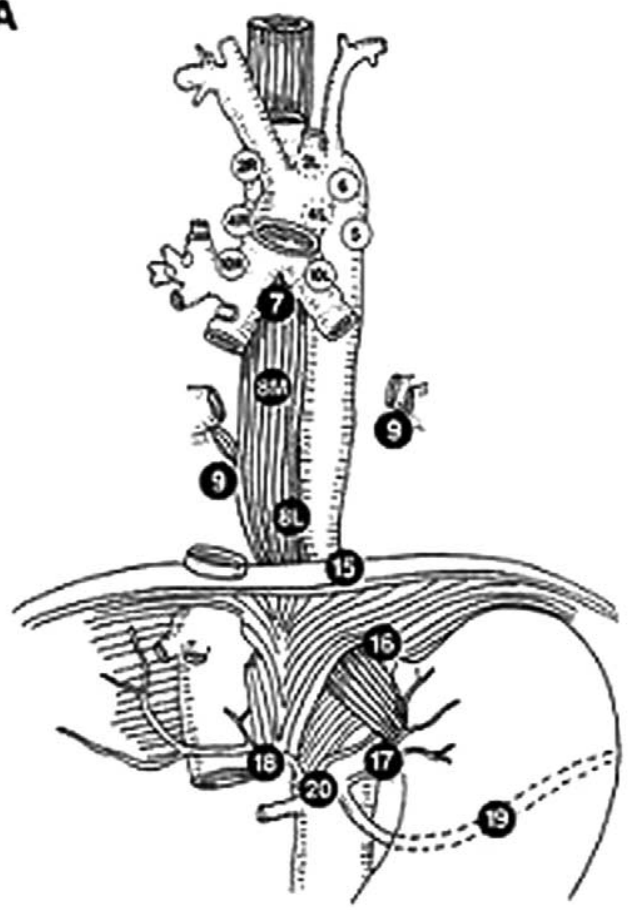

|B

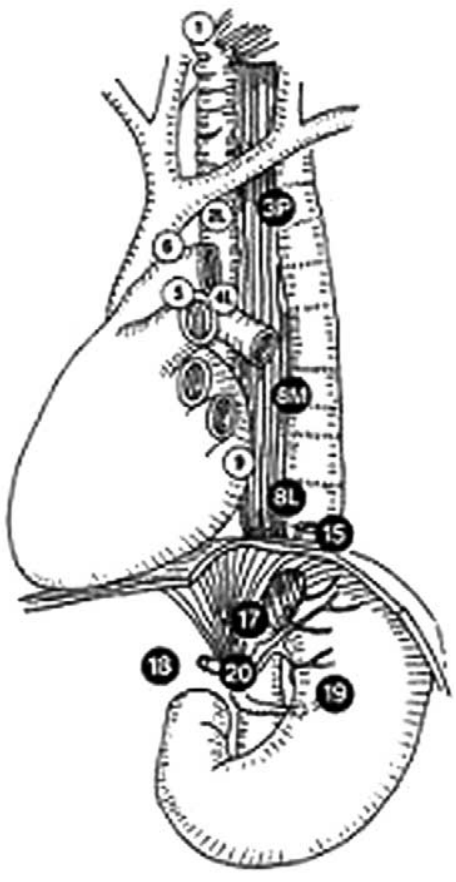

Figure 1. Illustration of the nodal stations assessed.

\begin{tabular}{|c|c|}
\hline Station & Location \\
\hline 2R Right upper paratracheal nodes* & $\begin{array}{l}\text { Between intersection of caudal margin of innominate artery with trachea and } \\
\text { the apex of the lung }\end{array}$ \\
\hline 3P Posterior mediastinal nodes* & Upper paraesophageal nodes, above tracheal bifurcation \\
\hline 4R Right lower paratracheal nodes* & $\begin{array}{l}\text { Between intersection of caudal margin of innominate artery with trachea and } \\
\text { cephalic border of azygos vein }\end{array}$ \\
\hline 7 Subcarinal nodes* & Caudal to the carina of the trachea \\
\hline 8M Middle paraesophageal lymph nodes* & $\begin{array}{l}\text { From the tracheal bifurcation to the caudal margin of the inferior pulmonary } \\
\text { vein }\end{array}$ \\
\hline 8L Lower paraesophageal lymph nodes* & From the caudal margin of the inferior pulmonary vein \\
\hline 9 Pulmonary ligament nodes* & Within the inferior pulmonary ligament \\
\hline 10R Right tracheobronchial nodes* & From cephalic border of azygos vein to origin of RUL bronchus \\
\hline 15 Diaphragmatic nodes* & Lying on the dome of the diaphragm, and adjacent to or behind its crura \\
\hline 16 Paracardial nodes* & Immediately adjacent to the gastroesophageal junction \\
\hline $17 \mathrm{~L}$ gastric nodes & Below diaphragm \\
\hline 18 Common hepatic nodes* & Along the course of the common hepatic artery \\
\hline 20 Celiac nodes* & At the base of the celiac artery \\
\hline
\end{tabular}

Modified from the Virtual Hospital: http://www.vh.org/adult/provider/surgery/EsophagealCarcinoma. *Nodes from these stations were required for entry to the study if patients were resected.

of the chest, abdomen, and pelvis; endoscopic ultrasonography with fine-needle aspiration (EUS-FNA); and positron emission tomography with fluoro-2-deoxy-D-glucose (FDG-PET). The decision to operate or give more chemotherapy often hinges on the interpretation of these tests. Thus we decided to evaluate the accuracy of these tests for the determination of $\mathrm{T}$ stage, nodal status, and distant M1 disease, as well as their ability to predict complete responders after neoadjuvant therapy.

\section{Patients and Methods}

From August 1, 2002, to June 1, 2004, all patients presenting to one general thoracic surgeon (R.J.C.) with suspected or biopsy-proved esophageal carcinoma were asked to sign a consent form to be in a prospective database that assessed the accuracy of initial and repeat chest, abdomen, and pelvis CT; EUS-FNA; and FDG-PET with an integrated PET/CT. The details of their postoperative care and longterm survival were also recorded. Patient demographics, medical 


\section{TABLE 1. Patient characteristics}

\begin{tabular}{|c|c|}
\hline & All patients $(n=48)$ \\
\hline Age, median (y) & 68 (range, 48-76) \\
\hline \multicolumn{2}{|l|}{ Sex } \\
\hline Male & $41(85 \%)$ \\
\hline Female & $7(15 \%)$ \\
\hline \multicolumn{2}{|l|}{ Types of radiation } \\
\hline$<5000$ cGy & $22(46 \%)$ \\
\hline$>5000 \mathrm{cGy}$ & $26(44 \%)$ \\
\hline \multicolumn{2}{|l|}{$\begin{array}{l}\text { Median duration between last date of } \\
\text { neoadjuvant therapy and: }\end{array}$} \\
\hline Repeat CT & $17 \mathrm{~d}$ \\
\hline Repeat EUS & $37 \mathrm{~d}$ \\
\hline Repeat PET & $27 \mathrm{~d}$ \\
\hline \multicolumn{2}{|l|}{ Pathology } \\
\hline Adenocarcinoma & $43(85 \%)$ \\
\hline Squamous cell carcinoma & $5(15 \%)$ \\
\hline \multicolumn{2}{|l|}{$\begin{array}{l}\text { Stage of cancer before neoadjuvant } \\
\text { treatment }\end{array}$} \\
\hline I (T1 N0 Mo) & 0 \\
\hline Ila (T2 No Mo, T3 No Mo) & $22(46 \%)$ \\
\hline Ilb (T0-2 N1 M0) & $5(10 \%)$ \\
\hline III (T3 N1 M0) & $15(33 \%)$ \\
\hline T4 (Any N M0) & $2(4 \%)$ \\
\hline IV (M1a) & $3(6 \%)$ \\
\hline IV (M1b) & $1(2 \%)$ \\
\hline \multicolumn{2}{|l|}{$\begin{array}{l}\text { Stage of cancer after neoadjuvant } \\
\text { treatment }\end{array}$} \\
\hline 0 (Complete responder) & $15(31 \%)$ \\
\hline I (T1 No Mo) & $5(10 \%)$ \\
\hline Ila (T2 No Mo, T3 No Mo) & $10(22 \%)$ \\
\hline Ilb (T0-2 N1 M0) & $4(8 \%)$ \\
\hline III (T3 N1 M0) & $2(4 \%)$ \\
\hline T4 (Any N Mo)* & $1(2 \%)$ \\
\hline IV (M1a) & $5(10 \%)$ \\
\hline IV $(\mathrm{M} 1 \mathrm{~b})^{*}$ & $6(13 \%)$ \\
\hline $\begin{array}{l}\text { No. of patients who underwent Ivor } \\
\text { Lewis esophagogastrectomy }\end{array}$ & $41+(88 \%)$ \\
\hline
\end{tabular}

CT, Computed tomography; EUS, endoscopic ultrasonography; $P E T$, positron emission tomography. *Two of the 6 patients with M1b disease had resected pathologically confirmed T4 disease. $†$ Some patients with $\mathrm{M} 1 \mathrm{a}$ or M1b disease underwent complete resection. history, physical examination findings, scan results, morbidity during neoadjuvant therapy, and final pathology results were collected as well. Separate forms were used to record the results of the CT, EUS-FNA, and FDG-PET/CT and pathologic information as it became available, and a blinded collector entered information prospectively into an Access database (Microsoft, Seattle, Wash). Both the prospective database used to store the data and this study were approved by the Institutional Review Board of the University of Alabama at Birmingham.

For inclusion in this study, requirements included the following: biopsy-proved esophageal cancer; initial chest, abdomen and pelvis CT, EUS-FNA, and FDG-PET/CT; neoadjuvant chemoradiotherapy; repeat CT, EUS-FNA, and FDG-PET/CT; and pathologic staging. Patients with tissue confirmation of recalcitrant or progressive nodal or metastatic disease who did not undergo complete resection were also included in this study. Only magnetic resonance imaging of the brain or bone was accepted as proof of metastatic M1b disease; otherwise, tissue biopsy was required. Patients who underwent resection had to have had lymphadenectomy performed, as shown in Figure 1.

Patients were excluded if they did not have all 3 imaging tests before esophagectomy; they underwent emergency esophagogastrectomy; they did not have repeat staging with an integrated PET/CT scan; they did undergo chest, abdomen, and pelvic CT with 5-mm columnated cuts with intravenous contrast; or they had EUS-FNA performed by an endosonographer other than M.A.E.

After initial staging, all patients in this study underwent cisplatinbased chemotherapy with concomitant radiotherapy. After the completion of their neoadjuvant treatment, patients were restaged with the same 3 staging tests described below. A stage was assigned by using the TNM staging classification system ${ }^{2}$ after each test. Because CT, EUS-FNA, and FDG-PET could not differentiate T1, T2, or T3 disease, the accuracy for each test was assessed for its ability to predict $\mathrm{T} 1$ to $\mathrm{T} 3$ disease from T0 and T4 disease. Because EUS-FNA could not assess M1b disease (except for certain locations, such as the left adrenal gland, the lower lobes of the lung, or parts of the liver), $\mathrm{M}$ disease could be recorded as Mx disease.

\section{CT Scans}

All scans had to be performed on a third-generation machine or greater, have 5-mm columnated cuts, and include the chest,

TABLE 2. Results of T stage as predicted with repeat CT, EUS-FNA, and FDG-PET compared with pathology*

\begin{tabular}{lcccc}
\hline & & \multicolumn{3}{c}{ T status predicted by test } \\
\cline { 3 - 5 } $\begin{array}{c}\text { Pathologic } \\
\text { results* }\end{array}$ & $\begin{array}{c}\text { No. of patients with } \\
\text { this pathology }\end{array}$ & \multicolumn{1}{c}{ CT } & T0 & FDS-FNA \\
\hline T0 & $16 \dagger$ & $\begin{array}{c}\text { Correctly predicted T0 in } 4 \\
\text { patients }\end{array}$ & $\begin{array}{c}\text { Correctly predicted T0 in } 3 \\
\text { patients }\end{array}$ & $\begin{array}{c}\text { Correctly predicted T0 in } \\
13 \text { patients }\end{array}$ \\
T1-T3 & 22 & 4 & 1 & 4 \\
T4 & 3 & 0 & 0 & 0
\end{tabular}

CT, Computed tomography; EUS-FNA, endoscopic ultrasonography with fine-needle aspiration; FDG-PET, fluoro-2-deoxy-D-glucose-integrated positron emission tomography. *Seven patients did not have their T status pathologically assessed. $\dagger$ This includes the 15 complete responders plus 1 patient who had TO N1 disease. 
abdomen, and pelvis. All films were read and interpreted by 1 of 4 chest radiologists. CT scans from outside institutions were allowed, but they had to be reread at the University of Alabama at Birmingham.

\section{EUS-FNA}

EUS was performed during conscious sedation, as previously described, ${ }^{10}$ and all tests were performed by a single experienced endosonographer (M.A.E.; $>2500$ EUS procedures). A radial echoendoscope (GF-UM130; Olympus America, Melville, NY) was first used to evaluate the presence or absence of lymphadenopathy. The examination started with full evaluation of the left lobe of the liver, the left adrenal gland (by imaging it from the fundus of the stomach and then gradually withdrawing it to evaluate the primary tumor), and all regional echo-visible lymph nodes. The perigastric, subhepatic, and celiac axis areas (M1a) were carefully evaluated for the presence of adenopathy. Once a suspicious lymph node (the endosonographic criteria for malignant lymph nodes involvement have been previously described ${ }^{11}$ ) was identified, the radial echoendoscope was removed, and a curvilinear echoendoscope (Olympus UC-30P or UCT 140) was inserted. EUS-FNA of the target lesion or lesions was performed as previously described. ${ }^{12}$ Peritumoral lymph nodes were not aspirated because of the risk of contamination from the primary tumor.

All EUS-FNAs were performed with 22-gauge adjustablelength Echotip needles (Wilson-Cook, Inc, Winston Salem, NC). Cytological diagnosis of the aspirated lesion (either of suspicious lymph nodes, M1a disease, or M1b disease) was reported as either positive for metastatic cancer or negative. If regional lymph nodes could not be aspirated because the primary tumor was intervening, the ultrasonographic characteristics were used to call the node positive or negative. The endosonographer (M.A.E.) was blinded to the CT report and to the FDG-PET report.

\section{FDG-PET/CT}

FDG-PET/CT was performed on a dedicated PET scanner with an integrated PET/CT system (GE Discovery LS PET/CT Scanner; GE, Milwaukee, Wis). Patients were asked to fast for 4 hours and then subsequently received $555 \mathrm{MBq}(15 \mathrm{mCi})$ of FDG intravenously, followed by PET after 1 hour. The most recent CT scan of the chest was available for visual correlation of the integrated
PET/CT result, but the reader (B.O.) was unaware of the EUSFNA-predicted TNM stage or of the TNM-predicted stage of the CT scan.

Maximum standardized uptake value (maxSUV) was determined by drawing regions of interest on the attenuation-corrected FDG-PET images around the primary tumor. The maxSUV was calculated by using the software contained within the PET/CT scanner and the following formula ${ }^{13}$ :

$$
\operatorname{Max} S U V=\frac{C(\mu C i / m L)}{\frac{I D(\mu C i)}{w(k g)}}
$$

where $\mathrm{C}$ is defined as the activity at a pixel within the tissue defined by a region of interest, and ID is defined as the injected dose per kilogram of the patient's body weight $(\mathrm{w})$. The percentage change of the maxSUV was calculated by using the following formula:

\section{MaxSUVintitial - MaxSUVfinal MaxSUVinitial}

A regional lymph node ( $\mathrm{N}$ disease or M1a disease if a celiac node), as well as M1b disease, was considered positive on FDGPET/CT scanning if the maxSUV was 2.5 or greater and the FDG-PET/CT report called the node malignant or highly suspicious for malignancy. In this study M1a disease was defined as celiac axis lymph node disease in patients with distal esophageal tumors.

\section{Statistical Analysis}

Data were stored by using an Access database (Microsoft) and analyzed with EpiInfo (CDC, Atlanta, Ga). Mortality was defined as any death occurring during the hospital stay or within 30 days postoperatively. Sensitivity, specificity, positive predicted value, negative predicted value, and accuracy were determined for CT, EUS-FNA, and FDG-PET/CT by using the pathology or biopsy results as the gold standard. Standard definitions were used to calculate these parameters. ${ }^{14}$ Differences between efficacy percentages were compared by using the test for proportions.

T status predicted by test

\begin{tabular}{|c|c|c|c|c|c|}
\hline \multicolumn{6}{|c|}{ T status predicted by test } \\
\hline \multicolumn{3}{|c|}{ T1, T2, T3 } & \multicolumn{3}{|c|}{ T4 } \\
\hline CT & EUS-FNA & FDG-PET & Ст & EUS-FNA & - \\
\hline 12 & 13 & 3 & 0 & 0 & 0 \\
\hline $\begin{array}{l}\text { Correctly predicted } \\
\text { T1-T3 in } 18 \text { patients }\end{array}$ & $\begin{array}{l}\text { Correctly predicted } \\
\text { T1-T3 in } 20 \text { patients }\end{array}$ & $\begin{array}{l}\text { Correctly predicted } \\
\text { T1-T3 in } 18 \text { patients }\end{array}$ & 0 & 1 & 0 \\
\hline 2 & 3 & 1 & $\begin{array}{l}\text { Correctly predicted } \\
\text { T4 in } 1 \text { patient }\end{array}$ & $\begin{array}{l}\text { Correctly predicted } \\
\text { T4 in } 0 \text { patients }\end{array}$ & $\begin{array}{l}\text { Correctly predicted } \\
\text { T4 in } 2 \text { patients }\end{array}$ \\
\hline
\end{tabular}




\section{Results}

Sixty-seven patients were eligible for this study over this time frame. Four patients refused participation, and 9 patients were eliminated because after the completion of their neoadjuvant therapy, they had evidence of progressive disease on the restaging tests but refused or did not undergo tissue biopsy. In addition, 2 patients could not get repeat FDG-PET/CT scans, and 4 patients were too ill or refused resection. The remaining 48 patients make up the cohort of this study. Patient characteristics are shown in Table 1. There were $2(4 \%)$ operative mortalities, and there was no morbidity or mortality with EUS-FNA.

\section{T Status}

Table 2 depicts the results of the T status for CT, EUS, and FDG-PET. As defined earlier, we allowed the endosonographer and radiologists to report a lesion as T1, T2, or T3 (because he could not differentiate tumor from posttreatment effect), and his test results were considered correct if the tumor was defined as T1, T2, or T3 on final pathology. This definition was used for all 3 staging modalities. When one evaluates the ability of a staging modality to correctly distinguish pathologic $\mathrm{T} 4$ from $\mathrm{T} 1$ to $\mathrm{T} 3$ disease, the negative predictive value is $90 \%, 87 \%$, and $95 \%$ and the accuracy is $76 \%, 80 \%$, and $80 \%$ for CT, EUS-FNA, and FDGPET/CT, respectively. There were only 3 patients with T4 disease.

\section{N Status}

Chest CT, EUS-FNA, and FDG-PET/CT are all able to predict the presence or absence of $\mathrm{N}$ status, M1a disease, and complete responders. The raw data for each staging modality is shown in Table 3, and the efficacy is seen in Table 4. As shown, FDG-PET/CT is more accurate for staging $\mathrm{N}$ disease than CT and EUS-FNA (93\% and $78 \%$ vs $78 \%$, respectively; $P=.04$ ).

\section{M1a and M1b Disease}

Six patients had pathologic M1a disease, and the results for each test are shown in Tables 3 and 4. In addition, 6 patients had M1b disease, and the results are shown in Table 5. FDG-PET/CT found unsuspected M1b disease in $4(8 \%)$ patients, falsely suggested it in $4(8 \%)$ others, and missed small (4-mm) nodular implants in the lung and in the omentum in 1 patient each.

\section{Complete Responders}

There were 15 (31\%) patients who had a complete response to neoadjuvant chemoradiotherapy. Table 4 compares the efficacy among chest CT, EUS-FNA, and FDG-PET/CT for complete responders (T0 N0 M0). FDG-PET/CT was more sensitive than EUS-FNA and CT (87\% vs $20 \%$ vs $20 \%$, respectively; $P=.01$ ) and more accurate ( $89 \%$ vs $67 \%$ vs $67 \%$, respectively; $P=.045)$. When FDG-PET/CT overstaged complete responders, all 3 patients had T1 N0 disease, whereas when EUS-FNA overstaged 12 of the 15 complete responders, it predicted $\mathrm{T} 2$ disease in 2 patients, T3 disease in 7 patients, and T4 disease in 3 patients. CT overstaged 11 of the 15 complete responders and predicted $\mathrm{T} 1$ disease in 5, T2 disease in 4, and T3 disease in 2.

There were 23 patients who had biopsy-proved N1 disease before neoadjuvant therapy, and 8 of them had a complete pathologic response. There were 25 patients whose disease was staged as N0, and 7 were complete responders.

\section{Effect of Response to Chemoradiotherapy on Change in MaxSUV}

The median change in the maxSUV on FDG-PET/CT as correlated to the pathology is shown in Figure 2. The median percentage decrease in the maxSUV in the 36 patients who were downstaged (15 complete responders and 21 others) was significantly higher than for the 12 patients who were not ( $47 \%$ vs $-8 \%$, respectively; $P=.03$ ).

\section{Discussion}

Despite the fact that few prospective randomized trials have shown a benefit for neoadjuvant therapy for esophageal cancer and some series that use esophageal resection alone have adequate survival, ${ }^{15}$ most institutions use it. Thus the interpretation of repeat staging tests affects the care of a large proportion of patients with this aggressive cancer. Patients who are deemed to have T4 disease or who have recalcitrant nodal disease are often denied resection on the basis of these test results. Yet there have been few prospective trials that have examined the accuracy of the 3 most common staging and restaging tests, CT, EUS-FNA, and FDG-PET, in one prospective study.

\section{T Status}

The accuracy of EUS-FNA for assessment of the T status for esophageal cancer before chemoradiotherapy has been well documented ${ }^{16}$ and is undisputed. It is minimally invasive, has little morbidity, and can also obtain tissue to assess $\mathrm{N}$ and M1a disease. At our institution, we have even been able to prove M1b disease in selected areas, such as both the right and left adrenal glands, the lower lobes of the lung, and parts of the liver. However, its accuracy after neoadjuvant therapy has been questioned.

Zuccaro and colleagues ${ }^{17}$ in 1999, Laterza and associates ${ }^{18}$ in 1999, and Beseth and coworkers ${ }^{19}$ in 2000 have all shown that EUS-FNA cannot tell $\mathrm{T} 1$ from $\mathrm{T} 2$ or $\mathrm{T} 3$ disease after chemoradiotherapy. However, Willis and colleagues ${ }^{20}$ in 2002 and Chalk and associates ${ }^{21}$ in 2000 showed that a $50 \%$ or greater decrease of cross-sectional area, as determined by 
TABLE 3. Data used to compute efficacy for CT, EUS-FNA, and FDG-PET

\begin{tabular}{|c|c|c|c|c|c|c|c|c|c|c|c|c|}
\hline & \multicolumn{4}{|c|}{ CT } & \multicolumn{4}{|c|}{ EUS-FNA } & \multicolumn{4}{|c|}{ FDG-PET } \\
\hline & $\begin{array}{c}\text { True } \\
\text { positive }\end{array}$ & $\begin{array}{c}\text { False } \\
\text { positive }\end{array}$ & $\begin{array}{c}\text { False } \\
\text { negative }\end{array}$ & $\begin{array}{c}\text { True } \\
\text { negative }\end{array}$ & $\begin{array}{c}\text { True } \\
\text { positive }\end{array}$ & $\begin{array}{c}\text { False } \\
\text { positive }\end{array}$ & $\begin{array}{c}\text { False } \\
\text { negatives }\end{array}$ & $\begin{array}{c}\text { True } \\
\text { negatives }\end{array}$ & $\begin{array}{c}\text { True } \\
\text { positive }\end{array}$ & $\begin{array}{c}\text { False } \\
\text { positive }\end{array}$ & $\begin{array}{c}\text { False } \\
\text { negative }\end{array}$ & $\begin{array}{c}\text { True } \\
\text { negative }\end{array}$ \\
\hline N1 & 1 & 2 & 7 & 31 & 1 & 2 & 7 & 31 & 5 & 0 & 3 & 33 \\
\hline NO & 31 & 7 & 2 & 1 & 31 & 7 & 2 & 1 & 33 & 3 & 0 & 5 \\
\hline M1a & 0 & 0 & 6 & 42 & 2 & 0 & 4 & 42 & 2 & 1 & 4 & 41 \\
\hline CR & 4 & 3 & 11 & 30 & 3 & 2 & 12 & 31 & 13 & 4 & 2 & 29 \\
\hline
\end{tabular}

Note: $\mathrm{N}$ status was not pathologically assessed in 7 patients. CT, Computed tomography; EUS-FNA, endoscopic ultrasonography with fine-needle aspiration; FDG-PET, fluoro-2-deoxy-D-glucose-integrated positron emission tomography; N1, positive lymph nodes; NO, lymph nodes without cancer; $M 1 a$, metastatic cancer in celiac axis lymph node; $C R$, complete pathologic responders.

TABLE 4. Comparison of efficacy of CT, EUS-FNA, and FDG-PET for nodal status, M1a disease, and complete responders

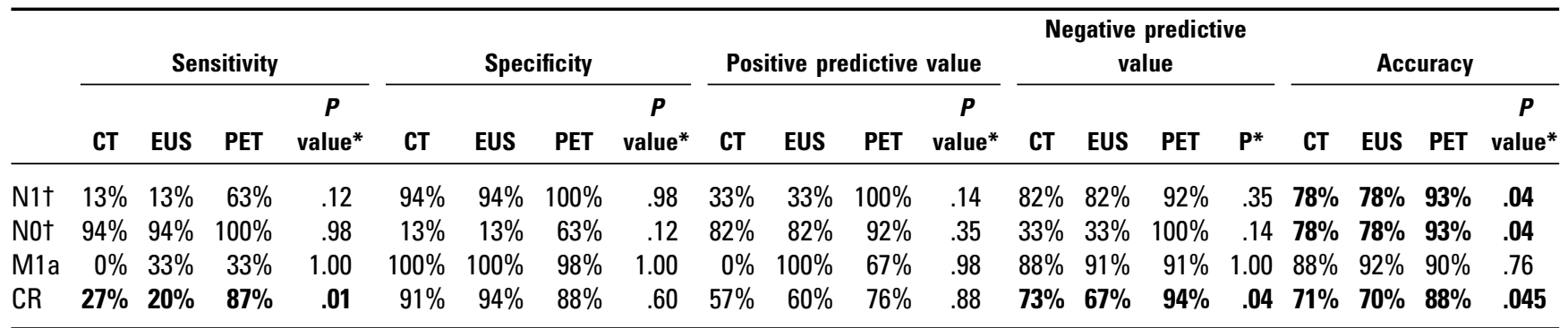

CT, Computed tomography; EUS-FNA, endoscopic ultrasonography with fine-needle aspiration; FDG-PET, fluoro-2-deoxy-D-glucose-integrated positron emission tomography; M1a, metastatic cancer in celiac axis lymph node; N1, positive lymph nodes; NO, lymph nodes without cancer; $C R$, complete pathologic responders. $* P$ value refers to EUS-FNA versus FDG-PET. $† \mathrm{~N}$ status was not assessed in 7 patients.

means of EUS, is a good predictor of response. We believe the distinction of $\mathrm{T} 1$ to $\mathrm{T} 3$ disease has little clinical importance anyway because resection is invariably recommended for posttherapy $\mathrm{T} 1$ to $\mathrm{T} 3$ lesions if patients have N0 disease. The important clinical question is determining who has T4 disease and perhaps should not undergo an operation because an R0 resection is not possible. Thus we evaluated the accuracy and negative predictive value of the restaging tests to answer this specific question. Because complete responders are a separate category that might benefit the most from resection, ${ }^{22,23}$ they were evaluated separately.

We were surprised to find that the negative predictive value is best for FDG-PET/CT at $95 \%$. This might be because our study features an integrated PET/CT system as opposed to dedicated PET alone. This might be an important distinction of our study. We also found that none of the 3 tests were very good for ruling out T4 disease. In fact, making the clinical effect of our findings even more difficult to interpret is the fact that we were able to completely resect all 3 patients who turned out to have unsuspected $\mathrm{T} 4$ disease with negative margins. EUS-FNA defined 1 patient's disease as T3 and the other 2 patients' diseases as T2. One might argue that these patients had resectable T4 lesions, and thus EUS was correct in the sense that they were resectable, but the clinical effect of resected $\mathrm{T} 4$ versus nonresected $\mathrm{T} 4$ disease after neoadjuvant therapy is unknown. Thus we recommend that if a patient's risk for surgical intervention is low, it makes sense to explore
TABLE 5. Results of chest, abdomen, and pelvis CT and FDG-PET for predicting M1b disease

\begin{tabular}{|c|c|c|c|c|c|c|c|c|}
\hline & \multicolumn{2}{|c|}{$\begin{array}{c}\text { True } \\
\text { positive }\end{array}$} & \multicolumn{2}{|c|}{$\begin{array}{c}\text { False } \\
\text { positive }\end{array}$} & \multicolumn{2}{|c|}{$\begin{array}{c}\text { False } \\
\text { negative }\end{array}$} & \multicolumn{2}{|c|}{$\begin{array}{c}\text { True } \\
\text { negative }\end{array}$} \\
\hline & СТ & PET & СT & PET & CT & PET & CT & PET \\
\hline Location & & & & & & & \multirow{5}{*}{\multicolumn{2}{|c|}{$\begin{array}{c}\text { Not } \\
\text { applicable }\end{array}$}} \\
\hline Liver & 3 & 3 & 2 & 2 & - & 一 & & \\
\hline Lung & - & 1 & 1 & 1 & 2 & 1 & & \\
\hline Adrenal & - & - & - & 1 & - & - & & \\
\hline Omentum & - & - & - & - & 1 & 1 & & \\
\hline
\end{tabular}

$\overline{C T \text {, Computed tomography; FDG-PET, fluoro-2-deoxy-D-glucose-integrated }}$ positron emission tomography.

him or her to attempt R0 resection, even if the staging tests suggest T4 disease. More studies are needed to further examine these important questions not answered in this trial.

\section{Nodal Disease}

Importantly, Rice and coworkers ${ }^{24}$ in 2001 showed that patients with recalcitrant $\mathrm{N}$ disease after neoadjuvant therapy have a 5 -year survival of about $12 \%$ compared with $37 \%$ in those who did respond. Thus the ability to identify residual $\mathrm{N}$ disease also has clinical importance because some surgeons might choose not to resect. We found that FDG-PET/CT is superior to EUS-FNA and CT 


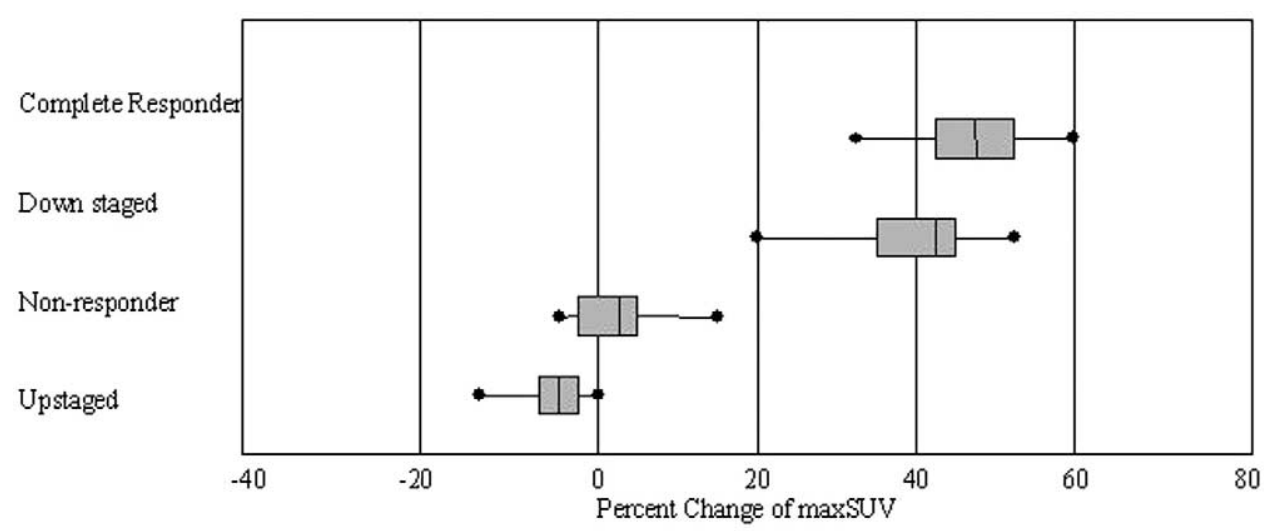

Figure 2. Median percentage decrease in maxSUV on repeat FDG-PET after neoadjuvant therapy.

for its ability to predict the presence or absence of metastatic nodal disease. EUS-FNA falters because oftentimes it cannot obtain aspirates from regional lymph nodes because of intervening tumor. Moreover, the echogenic characteristics alone of a node might not be as reliable after radiation as they are before. CT is inaccurate because the radiologic response of a lymph node often does not equate with the pathologic response. Thus metabolic information blended with anatomic information as afforded from an integrated PET/CT system, as opposed to pure anatomic information from EUS-FNA or $\mathrm{CT}$, might be superior. We have already shown the advantage of integrated PET/CT over dedicated PET visually correlated with $\mathrm{CT}$ in a prospective randomized study in patients with non-small cell lung cancer. ${ }^{25} \mathrm{Fi}-$ nally, if one believes that complete resection of recalcitrant metastatic nodes is warranted and important, one might be more likely to choose an Ivor Lewis instead of a transhiatal approach for a patient with an FDG-PET/CT result that suggests metastatic nodal disease.

FDG-PET results have been shown to be difficult to interpret after radiotherapy, and the best time to repeat an FDG-PET scan on a patient still remains unproved. In this report the median time between the completion of radiotherapy and the repeat FDG-PET/CT scan is 27 days. Our numbers are too low to perform a dose-response or a timedependent analysis, but our preference is to wait at least 3 weeks before performing the second FDG-PET/CT scan. Importantly, it must be stressed that a negative FDGPET/CT result of a regional lymph node after neoadjuvant therapy is not proof of benignancy, nor is a positive FDG$\mathrm{PET} / \mathrm{CT}$ result proof of cancer. It merely provides targets for biopsy to rule out cancer.

The ability of FDG-PET (not necessarily FDG-PET/CT) to discover unsuspected M1b disease is currently being studied in a multi-institutional prospective trial under the guise of the American College of Surgeon's Oncology Group Trial Z0060. Pierre and colleagues ${ }^{26}$ in 2004 found that FDG-PET upstaged $20 \%$ of 74 patients and correctly downstaged 5\%. However, he also found $7 \%$ false-positive results and $4 \%$ false-negative results. In this series we found that FDG-PET/CT discovered M1b disease in 4 (8\%) patients but was also falsely positive in $4(8 \%)$ patients. The results of Z0060 might provide answers as to the staging advantages provided by FDG-PET for M1 disease and balance them against the increased cost and morbidity of investigating false-positive results.

\section{Complete Responders}

Patients who undergo complete resection and who are found to be complete responders have a favorable prognosis. ${ }^{22,23}$ In our series 15 (31\%) of the 49 patients were complete responders, and EUS-FNA overstaged all but 3 of them. Interestingly, Zuccaro and associates ${ }^{17}$ in 1999 reported almost an identical incidence of complete response rate and rate of overstaging for EUS. The quantitative assessment of tumor metabolism by means of FDG-PET with maxSUV is a relatively new and exciting noninvasive technique to monitor a patient's metabolic response to a therapy. We found this objective measurement of metabolic activity to be more accurate than the change in a tumor's size. As we and others have shown, a significant decrease in the maxSUV in patients with non-small cell lung cancer $^{27}$ better correlates with a complete response than the change in size on CT or the absolute value of the maxSUV on repeat FDG-PET. This series, like those from Kato and coworkers ${ }^{28}$ and Downey and colleagues ${ }^{29}$ in 2002 suggest that this is also true in patients with esophageal cancer.

There are strengths and weaknesses to our study. Most of the previous studies evaluate the accuracy of a single modality over a long time period. This study offers a 
comparison of CT, EUS-FNA, and FDG-PET/CT in the same patient population over a short 2-year period using the best currently available technology and experienced readers. This might minimize confounders because of alterations in clinician experience, assignment of stage by multiple clinicians, and changes in technology. However, our study has a relatively small sample size, has been performed in a single institution only by one surgeon, and has only 3 patients with T4 disease, 5 with proved M1a disease, and 6 with M1b disease. Moreover, the strict entry criteria to this study, which required biopsy proof of progressive disease, eliminated 9 patients. Most of these patients had EUS-FNA that showed T4 nonresectable tumors, but because there was no pathologic proof of T4 disease (these patients could have all been in pathologic T0 stage), they were not included in this study. This rigid design might have negatively affected the true benefit of EUS-FNA. A multi-institutional trial is needed.

\section{Recommendations}

On the basis of the data presented above, as well as our experience, we recommend the following algorithm. We favor a repeat FDG-PET/CT scan (or, if not available, a CT scan of the chest, abdomen, and pelvis) to be performed no sooner than 3 to 4 weeks after the completion of the preoperative chemoradiotherapy. If FDG-PET/CT is available and if an initial FDG-PET/CT scan has been performed and all suspicious sites have undergone biopsy, we prefer it to CT. All possible M1b disease should be identified on either FDG-PET/CT, CT, or both, and all sites should be further investigated unless the lesion was initially investigated and has not changed. If M1a or M1b disease (in EUS-FNA obtainable areas) is suspected, we then recommend performing EUS-FNA to biopsy these areas, as well as to assess the $\mathrm{T}$ and $\mathrm{N}$ status. If no M1a or M1b disease is suggested, we still prefer repeat EUSFNA to assess the T status, as well as to obtain tissue of any residual $\mathrm{N}$ disease, despite the fact that our data do not prove its full usefulness for the T status. However, if a complete pathologic response is suggested by FDGPET/CT, then EUS-FNA adds little.

\section{Conclusion}

The surgeon must be aware of the limitations of each restaging modality. CT, EUS-FNA, and FDG-PET/CT cannot reliably differentiate the $\mathrm{T}$ status of esophageal cancer after neoadjuvant therapy, except for FDG-PET for T0 disease. None can reliably rule out T4 disease. FDG$\mathrm{PET} / \mathrm{CT}$ is superior to both chest CT and EUS-FNA for predicting nodal disease, and it is also better for predicting complete responders.

\section{References}

1. Jemal A, Murray T, Samuels A, Ghafoor A, Ward E, Thun MJ. Cancer statistics, 2003. CA Cancer J Clin. 2003;53:5-26.

2. Greene FL, Page DL, Fleming ID, et al. AJCC cancer staging manual. 6th ed. New York: Springer-Verlag; 2002.

3. Enzinger PC, Mayer RJ. Medical progress: esophageal cancer. $N$ Engl J Med. 2003;349:2241-52.

4. Burmeister BH, Smithers BM, Fitzgerald L, et al. A randomized phase III trial of preoperative chemoradiation followed by surgery (CR-S) versus surgery alone (S) for localized respectable cancer of the esophagus [abstract]. Prog Proc Am Soc Clin Oncol. 2002; 21:130a.

5. Urba SG, Orringer MB, Turrisi A, et al. Randomized trial of preoperative chemoradiation versus surgery alone in patients with locoregional esophageal carcinoma. J Clin Oncol. 2001;19:305-13.

6. Bosset J-F, Gignoux M, Triboulet J-P, et al. Chemoradiotherapy followed by surgery compared with surgery alone in squamous-cell cancer of the esophagus. N Engl J Med. 1997;337:161-7.

7. Nygaard K, Hagen S, Hansen HS, et al. Pre-operative radiotherapy prolongs survival in operable esophageal carcinoma: a randomized, multicenter study of pre-operative radiotherapy an chemotherapy: the second Scandinavian trial in esophageal carcinoma. World J Surg. 1992;16:1104-16.

8. Walsh T, Noonan N, Hollywood D, et al. A comparison of multimodal therapy and surgery for esophageal adenocarcinoma. $N$ Engl J Med. 1996;335:462-7.

9. Law S, Kwong D, Tung H, et al. Preoperative chemoradiation for squamous cell esophageal cancer: a prospective randomized trial [abstract]. Can J Gasteroenterol. 1998;12(suppl B):56B.

10. Hawes RH, Gress F, Kesler KA, Cummings OW, Conces DJ Jr. Endoscopic ultrasound versus computed tomography in the evaluation of the mediastinum in patients with non-small-cell lung cancer. Endoscopy. 1994;26:784-7.

11. Catalano MF, Sivak MV, Rice T, Gragg LA, Van Dam J. Endosonographic features predictive of lymph node metastasis. Gastrointest Endosc. 1994;40:442-6.

12. Gress FG, Savides TJ, Sandler A, et al. Endoscopic ultrasonography, fine-needle aspiration biopsy guided by endoscopic ultrasonography, and computed tomography in the preoperative staging of non-smallcell lung cancer: a comparison study. Ann Intern Med. 1997;127:60412.

13. Nabi HA, Zubeldia JM. Clinical applications of F18-FDG in oncology. J Nucl Med Technol. 2002;30:3-9.

14. Beck J. Likelihood ratios: another enhancement of sensitivity and specificity. Arch Pathol Lab Med. 1986;110:685-6.

15. Hagen JA, DeMeester SR, Peters JH, et al. Curative resection for esophageal adenocarcinoma: analysis of 100 en bloc esophagectomies. Ann Surg. 2001;234:520-30.

16. Rosch T, Classen M. Staging esophageal cancer. In: Van Dam J, ed. Gasterointestinal endosonography. Philadelphia: WB Saunders; 1999. p. $139-46$.

17. Zuccaro G, Rice TW, Goldblum J, et al. Endoscopic ultrasound cannot determine suitability for esophagectomy after aggressive chemoradiotherapy for esophageal cancer. Am J Gasteroenterol. 1999;94:906-12.

18. Laterza E, de Manzoni G, Guglielmi A, et al. Endoscopic ultrasonography in the staging of esophageal carcinoma after preoperative radiotherapy and chemotherapy. Ann Thorac Surg. 1999;67:1466-99.

19. Beseth BD, Bedford R, Isacoff WH, et al. Endoscopic ultrasound does not accurately assess pathologic stage of esophageal cancer after neoadjuvant chemoradiotherapy. Am Surg. 2000;9:827-31.

20. Willis J, Cooper GS, Isenberg G, et al. Correlation of EUS measurement with pathologic assessment of neoadjuvant therapy response in esophageal carcinoma. Gastrointest Endosc. 2002;55:655-61.

21. Chalk A, Canto MI, Cooper GS, et al. Endosonographic assessment of multimodality therapy predicts survival of esophageal carcinoma patients. Cancer. 2000;88:1788-95.

22. Bosing NM, Heise JW, Goretzki PE, Sarbia M, Roher HD. [Adenocarcinoma of the esophagogastric junction: prognostic factors and results of primary surgery] [in German]. Chirurg. 2004;26. Epub ahead of print

23. Heath EI, Burtness BA, Heitmiller RF, et al. Phase II evaluation of preoperative chemoradiation and postoperative adjuvant chemother- 
apy for squamous cell and adenocarcinoma of the esophagus. J Clin Oncol. 2000;18:868-76.

24. Rice TW, Blackstone EH, Adelstein DJ, et al. N1 esophageal carcinoma: the importance of staging and downstaging. $J$ Thorac Cardiovasc Surg. 2001;121:454-64.

25. Cerfolio RJ, Bryant AS, Ojha B. The accuracy of integrated PET-CT compared to dedicated PET alone for the staging of patients with non-small cell lung cancer. Ann Thorac Surg. 2004;78:1017-23; discussion 1017-23

26. Pierre AM, Heeren MD, Pieter LJ. Detection of distant metastases in esophageal cancer with F-FDG PET. $J$ Nucl Med. 2004;45:980-7.

27. Cerfolio RJ, Bryant AS, Winokur TS, et al. Repeat FDG-PET after neoadjuvant therapy is a predictor of pathologic response in patients with non-small cell lung cancer. Ann Thorac Surg. 2004;78:1903-9; discussion 1909

28. Kato H, Kuwano H, Nakajima M, et al. Usefulness of positron emission tomography for assessing the response of neoadjuvant chemoradiotherapy in patients with esophageal cancer. Am J Surg. 2002;184: 279-83.

29. Downey RJ, Akhurst T, Ilson D. Whole body FDG-PET and the response of esophageal cancer to induction therapy: results of a prospective trial. J Clin Oncol. 2003;21:428-32.

\section{Discussion}

Dr Steven DeMeester (Los Angeles, Calif). I would like to congratulate Dr Cerfolio both on his excellent presentation and the comprehensive article that he and his colleagues have prepared. The aim or objective of this study was to compare the accuracy of 3 modalities for restaging esophageal cancer after neoadjuvant therapy. Because neoadjuvant therapy is commonly used in the treatment of patients with esophageal cancer, this study is relevant, and the 3 modalities compared-CT, PET, and endoscopic ultrasonography-are available at most centers, and therefore the study objective is worthwhile. However, how this information should be used in practice is less clear. After neoadjuvant therapy, $75 \%$ to $80 \%$ of patients will have residual disease, and one could argue that precise local restaging is less important than just ruling out systemic metastatic disease, particularly because the goal or plan with neoadjuvant therapy is to follow up with surgical resection. I have several questions for Dr Cerfolio.

First, I have some questions pertaining to the details of PET scanning. Your patients all underwent PET scanning, as you pointed out, with the integrated PET/CT system. Presumably, this is what allowed the differentiation of the T stage of the tumor. Can you elaborate on how exactly PET/CT was used to determine the $\mathrm{T}$ stage, and in the absence of a fusion CT/PET system at a center, is it still possible to use PET scanning to define T stage?

Second, why were all 3 tests so poor at accurately identifying T4 tumors? And because the 3 patients with T4 tumors in your series all underwent successful surgical resection anyway, how important is it to determine the T stage after neoadjuvant therapy?

Third, all 3 tests were associated with false-positive and falsenegative assessment of nodal metastases, and this is in the setting of a study within an academic center. Out in the real world, accuracy rates are almost certain to be lower. What do you believe are acceptable accuracy rates when the results are going to be used for important patient management decisions?

Fourth, recent studies with either minimally invasive staging techniques or EUS-FNA have suggested that complete pathologic response rates with neoadjuvant therapy are lower in patients with pretherapy pathologically confirmed $\mathrm{N} 1$ disease. What percentage of patients with pathologically confirmed N1 disease had a complete response to neoadjuvant therapy in your series?

Fifth, why was the positive predictive value for complete response so poor and not significantly different with the 3 modalities? You did not present that; instead, you focused on negative predictive value. But is the positive predictive value not more important in this circumstance?

Sixth, there were 4 patients with true-positive results with systemic metastases found by fusion CT/PET scanning after neoadjuvant therapy, but there were 8 patients with false-positive or false-negative scan results. Because the number of false positive and false-negative PET scan results exceeded the true-positive results, is PET even worthwhile for assessing systemic metastatic disease after neoadjuvant therapy, or should we just be using CT, especially because most metastases were either in the lung or the liver, areas that are very well seen with computed axial tomography?

Lastly, do you have any information on the relative cost or cost/benefit ratio of each of these tests? And if you were at a center and had only the option of picking one test, which one would it be?

Dr Cerfolio. Thank you very much, Dr DeMeester. For time's sake, we might have to finish some of these questions over a beer later, but I will try to answer them all as quickly and succinctly as possible.

Your first question was as follows: Can PET tell us about $\mathrm{T}$ status, as opposed to PET/CT? I do not think it can. I think with the enhanced spatial resolution of integrated PET/CT, you can at least get an idea of the $\mathrm{T}$ status, like you can on a computed axial tomographic scan, but as we all know, it is not very good. The esophagus looks thickened. You do not know what is residual cancer and what is fibrotic, but neither does the endosonographer with EUS, as we found out in this study.

Second, you asked about the patients with T4 disease and why the modalities were so poor with that. I cannot tell you. Perhaps because this is a surgical series that required resection as an entry criterion, some T4 diseases were eliminated. Perhaps there is a difference between respectable T4 disease (thought to be T3 disease in this series or we probably would not have offered surgical intervention) than nonresectable $\mathrm{T} 4$ disease. The very rigorous design meant that 9 patients were eliminated; 7 of them had EUS criteria that showed T4 disease. Because I could not prove that the EUS was right, I could not include them in this study. They could have been complete responders, and the endosonographer could have been wrong, but those patients were not included.

The third question was about the false-positive and falsenegative results for nodal status. This is an important finding, especially for our medical colleagues. Just because a node is positive on a CT scan or PET scan, whether a patient has lung cancer or esophageal cancer, only means a biopsy of that lesion is required. Because EUS oftentimes cannot traverse the primary to get to the peritumoral lymph nodes to assess the node and because the echogenicity of the node after radiation and chemotherapy might not be a good predictor of malignancy or benignancy as it is before chemoradiotherapy, once must keep this in mind when interpreting the results of the restaging tests.

The fourth question concerns the complete responders. There were 15 complete responders; 8 patients were initially staged as 
having N1 disease, and 7 patients had N0 disease. A high number had biopsy-proved N1 disease initially.

The fifth question concerns why we reported the high negative predictive value and not the low positive predictive value. Actually, we report both, but the positive predictive value reflects prevalence of disease, and for this article, with a relatively small number of patients, it might not be as important.

Your sixth question concerns the role of PET for M1b disease. As we all know, there is a Z60 multi-institutional trial going on that is better able and equipped to accurately answer that question than this current series. We have placed more than 25 patients in that trial. One has to consider the cost of chasing after falsepositive results with extra scans and the anxiety that it causes patients versus identifying new M1b disease and avoiding unhelpful resections. I believe it is worthwhile, but I await the results of the $\mathrm{Z} 60$.

Finally, as to the costs and what we recommend, as I showed in one of the slides, we recommend an integrated PET/CT scan. Not only does it better identify N1 disease than EUS but it also allows one to generate the change in maxSUV, which we believe is an important predictor of pathologic response. Our future is clearly PET/CT and not PET, and I think that is what all of us will have, at least in North America.

Dr Richard Whyte (Stanford, Calif). I have one quick question. You ran through some of those slides very quickly, but I think somewhere there you said that patients with a complete response benefit from an operation.

Dr Cerfolio. Thank you. I said "might" benefit the most from resection, although some believe they might not even require resection.

Dr Whyte. "Might" benefit. I wanted you to expound on that a little bit because if you really have a pathologic compelte response, do you benefit from an operation at all?

Dr Cerfolio. That is a great question and one that requires a prospective randomized trial to accurately answer. What you are saying is what we just talked about last week at one of our conferences, and that is the question of whether a patient who has a complete response benefits from esophagectomy? The real question in the past has been how one knows who is a complete responder without resecting them? I believe that we now have presented data with the maxSUVs as a way of getting a good idea of who these patients are. It is not the absolute value of the repeat PET scan. It is the percentage decrease of the maxSUV. In our article on lung cancer, which is coming out in Annals later this year, we found it was a decrease of greater than $80 \%$ that predicted a complete response. In this study it was a decrease of about $50 \%$ or $60 \%$ as a good predictor of complete response. Now for the first time, maybe we can ethically do that study and randomize patients with a significant decrease in the maxSUV and who are undergoing a repeat EUS and CT scan that show a complete response and randomize these patients to observation or resection. Until that study is done, I cannot fully answer your question. At least now we have a way to identify potential patients for the study.

Dr Stephen Yang (Baltimore, $M d$ ). Just to follow up on Rich's comment, how many patients had a negative CT scan result and a negative PET/CT scan result? And when you present those data to the patient-the CT result is negative and the PET result is negative-how do you convince them to go on for a surgical operation?

Dr Cerfolio. Thank you. Well, I think of that up front, and therefore I tell them before they get their treatment that I have no data that even if they have a wonderful response that they should not undergo an operation. Thus I have them geared up for it preoperatively. We tell them we hope and pray that they get a great response, but they might not benefit from that without esophagectomy. I tell them I do not have definitive data to prove that, but that is my opinion and my belief. We have had 3 patients refuse operations because of this perceived clinical complete response, and all 3 have come back within 12 months with recurrent local disease and 1 with M1b disease. Until I see some data otherwise, that is practice and is what I am going to continue to tell them. I do not see why esophagectomy would be different from other cancers. If one can offer a safe operation and completely resect all disease, I believe that is best. 